\title{
Relative deficit of health services in Brazilian states and regions*
}

\section{Carlos Eduardo Gasparini**}

\author{
Francisco S. Ramos***
}

\begin{abstract}
The paper analyzes the allocation of health services to Brazilian states and regions. A relative service deficit indicator is constructed to achieve that goal, using equity-based criteria, which means equality of access for equal need. The Data Envelopment Analysis (DEA) is used to estimate the best service availability frontier for equal need. The results show great differences in the availability of health services among Brazilian states and regions. In regional terms, the situation of the South is the best one, whereas the North experiences the worst deficit of health services. These disparities highlight the importance of deficit assessment as an instrument to guide public action, especially in the Brazilian context, where the coverage and availability of health services is a constitutional rule.
\end{abstract}

Key Words: Health, Equality of Access, Relative Service ${ }_{\llcorner}$Deficit, Data Envelopment Analysis (DEA).

JEL Code: 118, I38 .

\footnotetext{
* The authors would like to thank two anonymous referees for helpf ul comments.

** Professor, Universidade Católica de Brasília - UCB. PhD in Economics - PIMES/UFPE. Address: SQN 214, Bloco H, apartamento 113, Asa Norte, Brasília - DF CEP 70873-080. E-mail: gasparini@ucb.br Telephone: +55 61 349-2925.

${ }^{* * *}$ Professor, PIMES/UFPE. PhD in Economic Sciences - CORE - Université Catholique de Louvain, Belgium. Address: Rua Prof. Antonio Coelho, 912, ap.301 - Cidade Universitária, Recife - PE. CEP 50740-020 E-mail: fsr@ufpe.br Telephone: +55 8199770977 . The autor thanks $\mathrm{CNPq}$ for financial support under grant n. 300317/93-0.
}

Brazilian Review of Econometrics Rio de Janeiro v.24, n 1, pp. 75-107 May 2004 
Relative deficit of health services in Brazilian states and regions

\section{Resumo}

O artigo avalia a distribuição de serviços de saúde entre Regiões e Estados brasileiros. Para isso, constrói um indicador do déficit relativo desses serviços, que usa como critério a equiidade de acesso, ou seja, mesma disponibilidade de serviços para necessidades iguais. A questão é abordada por meio da análise de envoltória de dados (DEA), por meio da qual se constrói uma fronteira de melhor disponibilidade de serviços para idênticas necessidades. Os resultados mostram que as diferenças na disponibilidade relativa de serviços são elevadas entre as Regiões e os Estados. Do ponto de vista regional, constatou-se que o Sul apresenta a melhor situação, enquanto o Norte dispõe do quadro mais desfavorável. Essas disparidades ressaltam a importância da avaliação dos déficits como instrumento orientador da atuação do poder público, especialmente no contexto brasileiro, onde a universalização da cobertura e do atendimento dos serviços públicos de saúde é preceito previsto na Constituição Federal.

\section{Introduction.}

In rare agreement, health and education are areas where public action is deemed necessary and positive for economy as a whole. Externalities, decreasing average costs, market imperfections, incomplete markets or information failures are some of the major arguments used to justify government action in these areas.

However, the provision of services by the government, especially in the health sector, raises some questions on how these services are allocated to citizens. Who should be attended to first? In other words, what criteria should be used to guide the allocation of public health services? After defining an allocation mechanism, how should it be put into practice? Given the complexity of the health sector, with distinct service needs and availability, evaluating the situation of a nation is not an easy task.

The aim of the present paper is to construct an indicator of the relative deficit of health services for Brazilian states, based on several availability and demand indicators. The Data Envelopment Analysis (DEA) is used to estimate the best service availability frontier for 
equal need, which assesses the disparities among Brazilian states, using equity-based criteria.

The paper is organized into six sections, including the introduction. The second section presents the reasons for the study. The third section describes the method used to construct the relative service deficit indicator for each Brazilian state. The fourth section shows the data set used in the calculations. The fifth section presents the results. Finally, the sixth section concludes.

\section{Motivation.}

Although several criteria that could guide the allocation of health services exist, equality and equity have been widely employed. Equality takes for granted that all individuals are equal and, therefore, should be treated equally. On the other hand, equity acknowledges that individuals may be different and proposes that services be allocated in such a way that the disparity between them could be reduced. This means equality of access only for equal need ${ }^{1}$.

There are several arguments about the use of these criteria, including the formulation of public health policies. On the one hand, equality translates into universal provision of services. On the other hand, equity means concentration of actions. The costs of universal provision are higher, but it warrants the indiscriminate provision of services. In its turn, the concentration of actions, which depends upon economic factors, employs the available resources in a given selection of beneficiaries, usually those who are at a greater disadvantage (poor people, minority groups, etc.).

It should be underscored that in a context in which the needs to be met are very similar, equality and equity virtually have the same

\footnotetext{
${ }^{1}$ Medeiros (1999) gives a detailed account of the principles of resource allocation in the health sector.
} 
Relative deficit of health services in Brazilian states and regions

meaning. However, in a scenario of marked socioeconomic disparities and lack of resources, as is the case of Brazil, this discussion is of vital importance.

To have an idea of the inequalities observed in Brazil, see some indicators regarding the availability of and demand for health services in 1999 (Table 1) ${ }^{2}$.

Table 1 - Brazilian Regions -

Availability of and Demand for Health Services - 1999

\begin{tabular}{|c|c|c|c|c|c|}
\hline & Der & mand & Service & Availability & \\
\hline STATE & $\begin{array}{l}\text { Infant } \\
\text { mortality (1) }\end{array}$ & $\begin{array}{l}\text { Cases of } \\
\text { tuberculosis } \\
\text { per 1,000,000 } \\
\text { inhab }\end{array}$ & $\begin{array}{l}\text { Doctors per } \\
1,000 \text { inhab }\end{array}$ & $\begin{array}{l}\text { Hospital } \\
\text { beds per } \\
1,000 \text { inhab }\end{array}$ & $\begin{array}{l}G D P \text { per } \\
\text { capita }(R £)\end{array}$ \\
\hline$B R A Z I L$ & 30,7 & 656,89 & 1,44 & 2,99 & 5.740 \\
\hline North & 30,2 & 523,42 & 0,63 & 2,02 & 3.380 \\
\hline Northeast & 46,0 & 705,63 & 0,82 & 2,80 & 2.671 \\
\hline Southeast & 21,2 & 786,48 & 2,05 & 3,13 & 7.843 \\
\hline South & 20,3 & 397,49 & 1,37 & 3,18 & 6.878 \\
\hline Central West & 21,8 & 358,44 & 1,27 & 3,54 & 5.421 \\
\hline
\end{tabular}

Source: Ministry of Health (DATASUS) and IBGE - Census 2000. (1) Number of deaths up to the first year of life per 1,000 live births.

Demand indicators - infant mortality and new cases of tuberculosis per 1,000,000 inhabitants - are shown in Table 1. By analyzing the data on infant mortality, which strongly indicate the general health of the population, it is possible to observe the disparities that exist in Brazil. Given the Brazilian average of 30.7 deaths per 1,000 live births, the southern region (with an average of 20.3 deaths) has

\footnotetext{
${ }^{2}$ For detailed assessments of the Brazilian health sector, see Marinho, Moreno \& Cavalini (2001), Medici (1997) and Barros, Piola \& Vianna (1996).
} 
less than $50 \%$ of the infant mortality rates found in the northeast (46.0).

Further analysis shows that disparities are not restricted to these two regions, although they are closely related to the level of wealth, as can be inferred from the GDP per capita. The situation is worse when we look at the incidence of new cases of tuberculosis. The larger number of new cases of tuberculosis are found in the southeast, the wealthiest region, followed by the northeast, the poorest region.

If health needs are dissimilar and complex, demand indicators support the notion about the large disparities that exist in Brazil ${ }^{3}$. The data on the number of doctors per 1,000 inhabitants show that the southeast has 3.25 times more doctors per capita than the north and 2.5 more doctors than the northeast. The situation is the same when it comes to the number of hospital beds per 1,000 inhabitants. The central western region has virtually twice as many hospital beds per capita as the northern region. It should be highlighted that the data grouped according to Brazilian regions hide many inequalities. State-by-state data reveal that Rio de Janeiro (3.2 doctors per 1,000 inhabitants), for instance, has 8.4 times more doctors per capita than Maranhão (0.38 doctors per 1,000 inhabitants).

Such contrasts, however, are not in harmony with the health guidelines established by the Brazilian Constitution. The Brazilian Constitution of 1988, article 194, states that the public administration is responsible for social security, including health services, based on the principle of universal coverage and provision; of selection and allocation of services; of equity in sharing costs, among others ${ }^{4}$.

Nevertheless, the disparities in the health sector show that these

\footnotetext{
${ }^{3}$ The availability indicators refer to inputs and not directly to health services. Although the relationship between them allows the use of the former one as indicator of the latter one, a distinction must be made between the concepts.

${ }^{4}$ Brazilian Constitution of 1988, art. 194, single paragraph, EC 20/98.
} 
Relative deficit of health services in Brazilian states and regions

goals are not easily met and that we are far from achieving them. In this context, the assessment of relative service deficit indicators is of paramount importance to restrict public policies that fall short of the goals proposed by the Brazilian Constitution.

\section{Methodology.}

The assessment of the relative availability of health services is not an easy task. First of all, the health sector is multifaceted and includes different types of services. Several indicators may be therefore used, but it is difficult to know exactly which one should be a priority. An alternative to deal with the situation is to construct synthetic indices for availability or access difficulty. However, this approach presents an aggregation problem, with at least three controversial questions: (a) which variables should be selected? (b) what is the relative weight of each variable (weighting method)? and (c) what is the functional form of aggregation?

Secondly, the issue leads to the problem of distributive justice, that is, choosing between the criteria that should guide the allocation of resources. A commonly employed equality-based criterion is the use of per capita indicators, which take the number of inhabitants into account. However, in a context of strong inequalities, the demand for health services is supposedly dependent upon a larger number of variables than upon the number of inhabitants only ${ }^{5}$. This results in a different demand for health services due to social and economic inequalities of the population, which adds to the multiple variables that have to be considered.

The present study uses the approach proposed by Puig-Junoy

\footnotetext{
${ }^{5}$ A bout the principles of equality and equity, Medeiros (1999), citing Amartya Sen, states that the key issue lies in answering the following question: "equality of what?" He concludes that the validation of an allocation depends on the definition of need.
} 
(1999), which consists of a new application of the data envelopment analysis (DEA). This method has been traditionally used to construct efficient frontiers ${ }^{6}$. By using the data set containing the demand for and availability of health services, we will construct the best service availability frontier for equal need.

This concept requires careful attention, since it is seldom used in Economics, even though the notion of frontier is quite common in its theoretical developments. An example is the production function, defined as the maximum amount of output that can be obtained from inputs. Likewise, we may use the cost function as another example. This function provides the minimum costs for a certain amount of output, given input prices. In both cases, the notion of frontier is present, that is, there is a maximum or a minimum limit for the established relations.

In case of the best service availability frontier for equal need, we evaluate the best services that can be possibly obtained, considering certain demands for health services. Thus, the demand for and availability of health services are compared. Therefore, the best available services for a certain level of need are analyzed.

Being located on the efficient frontier means having the best service available for a certain level of need, whereas being located below it means relative service deficit. Behind this rationale for service deficit is the idea that the same services should be made available for equal need, that is, the construction of the frontier relies on the distributive principle of equality. The best service availability frontier for equal need may be used to guide the equitable allocation of services, especially of public services. In the present study, the

\footnotetext{
${ }^{6}$ Examples of studies on the Brazilian health sector include those conducted by Freitas (2002), Marinho \& Façanha (2002), Marinho (2001), Marinho \& Façanha (2000) and Dubeux (2000). Other Brazilian studies include those carried out by Gasparini \& Ramos (2003), Mariano \& Sampaio (2002), Sampaio de Souza and Ramos (1999) and Marinho, Resende \& Façanha (1997).
} 
relative service deficit in the health sector can therefore be computed as the distance of each Brazilian state from the efficient frontier.

Some characteristics of the DEA model make it the suitable tool for the analysis intended here. DEA transcends some limitations found in other approaches ${ }^{7}$. Among these features, the following ones are noteworthy: i) it is a method that can handle multiple demand and multiple availability indicators, providing a synthetic indicator of relative service deficit ${ }^{8}$; ii) the weighting of variables does not have any exogenous influence on the process (weights are actually a result of the analysis); iii) no functional form is imposed on the frontier.

\subsection{Construction of "Best Service Availability Frontier for Equal Need".}

Let us suppose a society made up of several regions ${ }^{9}$, where each region is characterized by a set of needs, which we will call $n$, and by a set of service availabilities called $k$. We will use subscript " $i$ " $(i=1,2, \ldots, I)$ to indicate the region, subscript " $l$ " $(l=1,2, \ldots, L$ to indicate each need to be met and subscript " $j$ " $(j=1,2, \ldots, J)$ to designate the type of service available. Thus, each region " $i$ " has $L$ needs that have to be met $\left(n_{i}=\left(n_{i 1}, n_{i 2}, \ldots, n_{i L}\right), n_{i} \in R_{+}^{L}\right)$ and $J$ available services $\left(k_{i}=\left(k_{i 1}, k_{i 2}, \ldots, k_{i J}\right), k_{i} \in R_{+}^{J}\right)$. The aim of the analysis is to construct a frontier that indicates the best service availability for a certain level of need.

Let us define the following relation between $n$ and $k: G R=$ $\{(n, k): n$ is satisfied by $k\}$. A family of available services $k$ that satisfies the level of need $n$ can be then defined as $P(n)=$

\footnotetext{
${ }^{7}$ See Seiford \& Thrall (1990) and Souza (2001).

${ }^{8}$ As pointed out by Ramos \& Sampaio de Souza (1999), the DEA model has a number of desirable properties in a performance indicator.

${ }^{9}$ In the literature on DEA, reference units are usually called DMU (Decision Making Units).
} 
$\{k:(n, k) \in G R\}$. Now, we can define the frontier that indicates the best service availability for equal need as Front $P(n)=$ $\{k: k \in P(n)$,

The relative service deficit, $Z$, (equiproportional) distance between the vector of needs and of service availability $(n, k)$ and the best service availability frontier. This measure can be defined as:

$$
Z(n, k)=\max \{\phi: \phi \bullet k \in P(n)\}
$$

In the expression above, $Z_{i}$

the best service availability frontier for equal need ${ }^{10}$. On the other hand, $Z_{i}$

$k_{i}$

to the region with more available services for the same level of need.

Operatively, $Z$ can be obtained for a particular region " 0 ", $Z_{0}$, from the vector of availabilities and needs $\left(n_{0}\right.$, linear programming problem ${ }^{11}$ :

${ }^{10}$ Strictly speaking, $Z=1$ is a necessary but not sufficient condition for $(n, k) \in$ Front $P(n)$. In addition, the sum of slack variables should equal zero so that the observation can be located on the frontier.

${ }^{11}$ This formulation corresponds to the output-oriented BCC (Banker, Charnes \& Cooper (1984)) model. 
Relative deficit of health services in Brazilian states and regions

$$
\begin{array}{ll}
Z_{0}(n, \quad \phi, \lambda & \\
\text { s.t. } & l=1, \ldots, L \\
-n_{0 l}+\sum_{i=1}^{I} n_{i} & j=1, \ldots, J \\
\phi k_{0 j}-\sum_{i}^{I} k_{i j} & \\
\sum_{i=1}^{I} \lambda_{i}=1 & \\
\lambda_{i} \geq 0 &
\end{array}
$$

Solving problem (2) for each region (i.e.: I times), the best service availability frontier can be identified, and the relative service deficit for each region can be measured. The weights attributed to the vectors of needs and availabilities $\left(\lambda_{i}\right)$ are those that minimize the distance between each region and the best service availability frontier.

The previous model is service-oriented and supposes variable returns to scale. Service orientation results from the necessity to evaluate in which measure the services should be increased, if necessary, so that a certain region is located on the frontier according to its needs ${ }^{12}$. On the other hand, the hypothesis of variable returns to scale allows adjusting possible size differences between regions, which certainly occurs in the Brazilian case.

${ }^{12}$ An alternative would be directing the model towards needs, which would indicate the proportion by which these needs should be reduced so that a given unit could be located on the frontier. As a public policy option, trying to reduce social demands is far less feasible than seeking to increase the availability of services. 
The situation of health care services in Brazil is complex and may be characterized by a large number of dimensions. The vector of availabilities should contemplate all those services made available to society, and the vector of needs should include all demographic, epidemiological, social and economic aspects that may influence them. Although the previously discussed methodology is appropriate for dealing with multiple variables, it is necessary to define which of these variables should be selected for the analysis. As the number of variables is greater than the number of regions to be analyzed, most of these regions might be placed on the best availability frontier.

A way to solve this problem is to use the principal component analysis, a statistical method for reducing the dimensionality of the data set and selection of variables ${ }^{13}$.

\subsection{Principal Components ${ }^{14}$.}

Let's assume a set of $p$ variables observed on $q$ elements, forming data set $X(q \times p)$. The aim of the principal component analysis is to describe the configuration of elements in the space of the variables, where the principal components determine the directions of larger variation of the observed points. The first principal component $\left(C_{1}\right)$ is a linear combination of $X$ that explains the greatest amount of variation. The second principal component $\left(C_{2}\right)$ is another linear combination of $\mathrm{X}$ with the second largest amount of variation, being orthogonal to $C_{1}$, and so on and so forth. The variance of principal components corresponds to the eigenvalues of the sample covariance

\footnotetext{
${ }^{13}$ The problem could be circumvented by using other techniques such as bootstrapping. See, for instance, Efron (1979) and Grosskopf (1996). Alternatively, Marinho, Resende \& Façanha (1997) use factorial analysis to explore dimensions that are common in the data set.

${ }^{14}$ Souza (1988) gives a detailed account of the analysis. A simpler approach is found in Kubrusly (2002).
} 
Relative deficit of health services in Brazilian states and regions

matrix of $X$. The coefficients associated with each variable are the corresponding unit eigenvectors.

The determination of components $C_{1}, C_{2}, \ldots, C_{p}$ results in decreasing variances due to the increasing restriction of noncorrelation between them. Thus, the last components have such small variations that they may be disregarded. This way, we may reduce the initial dimension of the problem and maintain only one part of the principal components, since they describe most of the total variance of the set of $p$ variables.

There are some alternative criteria for the selection of the number of principal components to be maintained in the analysis ${ }^{15}$. In the present study, the selection of principal components was based on the proportion of variance explained by each of the components. The subset of variables selected consists of a summary of the variance of the whole set without loss of relevant information.

Using this reduction of dimensionality, the first solution to the problem of selection of variables to be used in the determination of the best service availability frontier would be the replacement of the observed variables for the first principal components extracted from the sample. However, the application of this solution to problem (2) runs into the following difficulty: the principal components have positive and negative values and the vectors $n$ and $k$ were defined only for positive values.

The existence of negative variables in DEA models may cause problems to the determination of efficiency indicators, including situations in which its calculation might collapse. Some authors addressed the issue and its consequences and developed alternatives to tackle the problem. The suggested procedures are usually based

\footnotetext{
${ }^{15}$ Other usual criteria, besides the one employed herein, are: eigenvalue equal to 1 (one), scree test and the interpretability criterion.
} 
on invariance properties of efficiency measures in relation to affine transformations of the variables ${ }^{16}$.

In the present study, we will use an alternative procedure based on the characteristics of the approach employed herein, since for each principal component $C_{i}=a_{1 i} X_{1}+\ldots+a_{p i} X_{p}$, we may show that $\operatorname{Cov}\left(X_{j}, C_{i}\right)=\lambda_{i} a_{j i}$, where $\lambda_{i}=\operatorname{Var}\left(C_{i}\right)$. The sign and size of $a_{j i}$ indicate the direction and contribution of the $j_{t h}$ variable for the $i_{t h}$ component. Thus, the higher the coefficient $a_{j i}$, the higher the association between variable $j$ and component $i$. This way, we may establish as a criterion for the reduction of dimensionality, in case of the estimation of the best service availability frontier, the replacement of each of the principal components selected by the respective variable for the coefficient with the highest absolute value, since this variable is more representative of the variability of the respective principal component ${ }^{17}$.

\section{Data Set.}

The data set used for the estimations of the deficit of health services in Brazilian states consisted of 57 variables, of which 13 describe the availability (provision) of health services $(J=13)$ and 44 indicate the needs (demands) found in each Brazilian state $(L=44)$.

${ }^{16}$ Charnes et al. (1985) show that any affine transformation of the data can be applied without changing the results in case of additive models. In BCC models, Ali \& Seiford (1990) show that this type of transformation can be applied without changing the definition of efficient units. Pastor (1996) generalizes the previous results and concludes that output-oriented BCC models are invariant in terms of affine transformations of inputs, and the ones that are input-oriented are invariant to transformations in the outputs.

${ }^{17}$ As pointed out by Puig-Junoy (1999), the use of information obtained from the principal component analysis corresponds to the introduction of restrictions to the mathematical programming problem. First, he says that the principal component analysis provides additional information on the relative importance of each component; secondly, he declares that it allows overcoming the problem of selection of variables for the model. 
This set of variables comprises three years: 1997, 1998 and 1999. All variables were considered as fraction of the population in order to take the differences of the population into account. The webpage of DATASUS accessed between April and May 2002 was used as data source.

The service availability variables are subdivided into two groups: health professionals ( 5 variables) and number of hospital beds available $(8 \text { variables })^{18}$. Appendix A provides the full list of service availability variables.

The demand variables include three groups of indicators: morbidity and risk factors (19 variables), mortality (11 variables) and social, economic and demographic aspects (14 variables). Appendix $\mathrm{B}$ presents the full list of the demand variables.

When selecting the variables we sought to include the largest number of indicators for the 27 Brazilian states (including Distrito Federal), covering the largest possible number of years. However, Roraima did not provide some information on several indicators, and therefore we decided not to include this state in our sample. The deficits were therefore calculated for the remaining 26 Brazilian states $(I=26)$.

The treatment given to service availability variables deserves special attention. We may argue that only the availability of public services should be considered as it is the duty of the government to disseminate the coverage of health care services. Nevertheless, this set of indicators should represent all the resources made available to the population directly by the government or subcontracted to private sector by the government. Historically, the Brazilian health system has hired private services on a large scale in order to meet

\footnotetext{
${ }^{18}$ It should be underscored (see note 3) that input data are being used as indicators of health services. There must be a clear distinction between the concepts, though.
} 
the demand of the public sector. This has determined a strong dependence of public health services on the private sector ${ }^{19}$.

On the other hand, the distribution of public hospital beds and the contracting of private hospital beds is not homogeneous among Brazilian states ${ }^{20}$. This way, if we consider only the public availability of hospital beds, or any other indicator based only on the official availability of infrastructure, there would be a strong noise regarding the actual availability of public services in each of the Brazilian states. Moreover, no other statistical information was found that could allow the proper specification of public services, either provided by the public health system or hired ${ }^{21}$.

In this context, we opted to consider the overall deficit of health services (both public and private). Two factors justify this choice. First, the difficulties in properly specifying the public provision of health services in Brazil. Secondly, because the overall deficit serves as a more appropriate guidance for the equity-based criteria, according to which the same service (either public or private) should be made available for equal need ${ }^{22}$. Thus, the overall deficit can be considered to better explain the differences in the health needs of distinct Brazilian regions. Consequently, it may be used as an appropriate indicator of the direction a compensatory public availability

\footnotetext{
${ }^{19}$ Marinho, Moreno \& Cavalini (2001) point out that hired hospitals accounted for $1 / 3$ of admissions and $28 \%$ of the total value spent by the Unified Health System (SUS) in Brazil in 1997 and 1998.

${ }^{20}$ The same authors mentioned above state that hired services are more frequent in the South and Southeast, while public health services are more common in the North and Northeast. The Central West shows the best proportionality between public and private health services.

${ }^{21}$ An alternative is to consider the amounts spent by SUS in each of the states. The complexity of services and their costs may be a complicating factor, since they change from region to region.

${ }^{22} \mathrm{An}$ issue that may arise here is that there is no use in providing private health services if the population cannot afford them. However, the provision of private health services is more common in wealthier regions.
} 
Relative deficit of health services in Brazilian states and regions

of services should take.

Nevertheless, the indicators used here have some limitations that should be given due attention. First, a considerable part of the private sector does not get in contact with the public health system (the so-called Unified Health System, aka SUS), which may cause distortions, especially because the profile of this part of the private sector and of its users may vary considerably in different Brazilian regions. On top of that, the indicators do not include the differences related to the complexity of health services, or aspects such as hospital readmissions, the action of community-based health agents and the Family Health Program, among others.

Once the data set was defined, we applied the principal component analysis in order to determine the best summary of data about the availability of and demand for health services. For the selection of variables, we decided to use only the principal components that represented at least $5 \%$ of the sample variance. After that, for each principal component, we selected the variable containing the coefficient with the highest absolute value.

The result of the selection among availability indicators, considered for the three-year sampling period, led us to choose the following variables (the order of the principal component is shown in parentheses): clinic beds per 10,000 inhabitants (1), psychiatric beds per 10,000 inhabitants (2), pediatric beds per 10,000 inhabitants (3) and nursing technicians per 1,000 inhabitants (4). The combination of these four components allows explaining $93.4 \%$ of the variance between availability variables. The results of the principal component analysis regarding the availability indicators are described in Appendix C.

Also considering the three-year sampling period, the following variables were chosen as demand indicators: new cases of dengue per $1,000,000$ inhabitants (1) and cases of typical work-related accidents 
per 1,000,000 inhabitants (2). These two variables together explain $94.1 \%$ of the sample variance regarding health service needs. The results of the principal component analysis regarding the demand variables are presented in Appendix D.

In both cases, the selected variables are important for their capacity to reduce the dimension of the problem, not for their individual explanatory value. They are indeed the best summary of the data set. However, the adopted procedure included variables that represent important dimensions for the Unified Health System. With regard to availability indicators, clinic beds usually correspond to one third of hospital admissions, whereas psychiatric beds account for the longest hospital stay. On the other hand, the selection of new cases of dengue among demand variables predicts the outbreak of the disease in 2001 and 2002 and reveals large disparities as to the Brazilian preventive health system.

\section{Results.}

The relative health service deficits in Brazilian states are shown in Table 2. They correspond to the solution to problem (2), using the representative data set specified in the previous item. The relative health service deficit $(\tilde{Z})$ is the arithmetic mean of the values obtained for the three-year sampling period. The indication of the mean value is due to the fact that the model does not include a specific term for noises that could occasionally be present in the data. This way, we can avoid possible distortions caused by measurement errors, omissions or even random noises.

Recall that $Z$ indicates the proportion that the service availability of a given state should be increased in order to have the same service availability as that obtained by the states ${ }^{23}$ located on the best

${ }^{23}$ Or through a convex combination between them. 
Relative deficit of health services in Brazilian states and regions

service availability frontier for equal need. For instance, $\tilde{Z}=1.121$ found for Rondnia means that the availability of health services in this state should be multiplied by 1.121 (a $12.1 \%$ increase) for it to be located on the best availability frontier. Another way to analyze the deficit is by inverting the radial index $(1 / \tilde{Z})$, shown in Table 2. This index indicates the proportion of services available for a certain state compared to those states located on the best availability frontier. Rondnia has $89.2 \%$ of the services provided in reference states regarding the best service availability for equal need.

By looking at Table 2, we see that eight Brazilian states are located on the best availability frontier for equal need $(\tilde{Z}=1)$ : Acre, Amapá, Maranhão, Piauí, Rio de Janeiro, Rio Grande do Sul, Goiás and Distrito Federal. These states (number 1 in the ranking shown in Table 2) are those where the availability of health services best meets the needs of the population.

On the other hand, the eight states in a worse situation are, in decreasing order of deficit: Sergipe, Alagoas, Amazonas, Espírito Santo, Bahia, Pernambuco, Amapá and Ceará. Except for Espírito Santo, all states belong to the North and Northeast regions. For the set of states, the average (relative) fulfillment of needs is of $82.6 \%$, with a minimum of $49.1 \%$ (Sergipe) and a maximum of $100 \%$.

This range is noteworthy. The value $\tilde{Z}=2.038$ (or $1 / \tilde{Z}=4.1 \%$ ) observed for Sergipe indicates that this state would have to more than double (a 103.8\% increase) the availability of health services in order to have the same service availability as some Brazilian states. We note, however, that Sergipe is not a unique case of disparity in the health sector. Alagoas (49.7\%), Amazonas (53.3\%), Esprito Santo $(55.3 \%)$ and Bahia $(57.9 \%)$ are other states that do not even reach $60 \%$ of the service availability found in other locations. 
Carlos Eduardo Gasparini and Francisco S. Ramos

Table 2 - Brazilian States and Regions Relative Availability of Health Services - average for 1997-1999

\begin{tabular}{|c|c|c|c|}
\hline State & $\tilde{Z}$ & $1 / \tilde{Z}$ & Ranking \\
\hline$\overline{\text { NORTH(1) }}$ & 1.460 & 0.685 & 5 \\
\hline Rondônia & 1.121 & 0.892 & 11 \\
\hline Acre & 1.000 & 1.000 & 1 \\
\hline Amazonas & 1.875 & 0.533 & 24 \\
\hline Pará & 1.581 & 0.632 & 20 \\
\hline Amapá & 1.000 & 1.000 & 1 \\
\hline Tocantins & 1.244 & 0.804 & 17 \\
\hline NORTHEAST(1) & 1.391 & 0.719 & 4 \\
\hline Maranhão & 1.000 & 1.000 & 1 \\
\hline Piaui & 1.000 & 1.000 & 1 \\
\hline Ceará & 1.336 & 0.749 & 19 \\
\hline Rio Grande do Norte & 1.195 & 0.837 & 15 \\
\hline Paraiba & 1.078 & 0.928 & 10 \\
\hline Pernambuco & 1.605 & 0.623 & 21 \\
\hline Alagoas & 2.013 & 0.497 & 25 \\
\hline Sergipe & 2.038 & 0.491 & 26 \\
\hline Bahia & 1.726 & 0.579 & 22 \\
\hline SOUTHEAST(1) & 1.350 & 0.741 & 3 \\
\hline Minas Gerais & 1.171 & 0.854 & 13 \\
\hline Espirito Santo & 1.809 & 0.553 & 23 \\
\hline Rio de Janeiro & 1.000 & 1.000 & 1 \\
\hline São Paulo & 1.189 & 0.841 & 14 \\
\hline SOUTH(1) & 1.054 & 0.949 & 1 \\
\hline Paraná & 1.145 & 0.874 & 12 \\
\hline Santa Catarina & 1.012 & 0.988 & 16 \\
\hline Rio Grande do Sul & 1.000 & 1.000 & 1 \\
\hline CENTRAL WEST(1) & 1.085 & 0.922 & 2 \\
\hline Mato Grosso do Sul & 1.202 & 0.832 & 9 \\
\hline Mato Grosso & 1.290 & 0.775 & 18 \\
\hline Goiás & 1.000 & 1.000 & 1 \\
\hline Distrito Federal & 1.000 & 1.000 & 1 \\
\hline AVERAGE(1) & 1.211 & 0.826 & - \\
\hline
\end{tabular}

(1) Population weighted average. 
With regard to regions, the South is better off. Of the three states that constitute this region, one is located on the best availability frontier (Rio Grande do Sul) and the other two have $98.8 \%$ (Santa Catarina) and $87.4 \%$ (Paraná) of the best availability of health services in Brazil. The region with the second best performance is the Central West, where on average $92.2 \%$ of the available services in the best areas are provided. Of the four states that constitute this region, two are located on the best availability frontier (Goiás and Distrito Federal). The Southeast, in its turn, has a service availability of 74.1

As previously predicted, the worst situations are found in the North and Northeast. In these regions, service availability accounts on average for only $68.5 \%$ and $71.9 \%$, respectively, of the best practices observed in Brazil. Despite the fact that some states have a different performance (this is the case of Acre in the North and Maranhão and Piauí in the Northeast, located on the best availability frontier), the highest deficits are found in these regions. Among the eight states in a worse situation, seven belong to these regions. On the other hand, considering the states below the Brazilian average, eight out of ten states in this situation belong to the North and Northeast.

The previous scenario shows large disparities between Brazilian states and regions*. Since the most unfavorable realities are observed in these noticeably underprivileged regions, one wonders if the deficit levels have some relation with the level of wealth of the states. In an attempt to shed some light on this issue, we calculated the correlation coefficient (Pearson's $r$ ) between the GDP per capita of Brazilian states in 1999 and the average deficit of health services $(\tilde{Z})$. The

*Although we focus on the inequalities of health services in Brazilian states, we should expect such inequalities to be more pronounced in Brazilian towns, especially in the North and Northeast regions. 
result found was $r=-0.204$. The negative value indicates that there is an inverse relationship between the variables (significantly different from zero to $10 \%$ ). In other words, the higher the GDP per capita of the state, the lower the deficit of health services. The low absolute value, however, shows a weak correlation. This result suggests that although the inverse relationship between deficit and GDP per capita may have some influence, there are several other factors that could interfere in this situation.

Based on the previously described scenario, we may note a situation that clearly contrasts with the guidelines for health services established by the Brazilian Constitution. The universal provision of health services is one of these guidelines. The idea of universal provision stems from the concept of equality and includes an ambitious provision of health services to the population. However, even by using a simpler concept such as that of equity, we have a quite unequal situation. This shows the enormous distance between intentions and Brazilian reality.

On the other hand, such contrast shows the importance of the results obtained here as possible guiding principles for public policies with compensatory guidance of regional inequalities. This occurs because these results clearly show where the largest problems are. If article 194 of the Brazilian Constitution is to be followed, this situation could not be disregarded.

Nevertheless, these results should be interpreted with caution. First, the approach uses indicators that represent a complex and multifaceted area, which quite often, go unnoticed in a quantitative analysis. Furthermore, quantity is not the same as quality of services. In a sector in which the complexity of services may vary considerably, the same number of beds may have a different impact. The aggregation of variables per state plays a restrictive role. In this regard, the situation in towns or cities may be quite peculiar. In this 
Relative deficit of health services in Brazilian states and regions

case, some technical issues should be also considered, such as the low number of years for which information was collected, the paucity of data about public health, the descriptive and deterministic nature of the model, among others. All of these factors certainly have an impact on the obtained results and should not only be taken into account in the analysis, but they should also be seen as indicative signs of future improvement.

Nonetheless, the present study aims at clearly indicating the areas relatively more underprivileged and allows drawing attention to a relevant issue in the discussion about the availability of public health services in Brazil: the marked inequalities observed. In a country such as Brazil where most of the population relies on public health services, the proper allocation of resources is of paramount importance. The construction of service deficit indicators is an important tool in guiding compensatory public policies. Undoubtedly, the reduction of regional health inequalities is related to other relevant issues, such as the availability of funds, decentralized actions and efficiency in service availability. However, the identification of Brazilian areas where deficiencies are more severe is the first step towards the establishment of public health policies.

\section{Conclusions.}

The aim of the present paper was to evaluate the allocation of health services in Brazilian states and regions. The DEA model was used to construct the best availability frontier for equal need. The establishment of this frontier allowed us to assess the relative deficit of health services in each state, using equity-based criteria.

The results showed that large disparities exist in the availability of health services in Brazilian states. On average, approximately $82.6 \%$ of services available on the frontier were provided. However, the variation observed was quite significant. States such as Sergipe, 
Alagoas, Amazonas, Esprito Santo and Bahia have less than $60 \%$ of the services provided in states with the best availability. This is the situation of Acre, Amapá, Maranhão, Piauí, Rio de Janeiro, Rio Grande do Sul, Goiás and Distrito Federal.

Regionally speaking, the situation of the South was the best, followed by the Central Western region. The Southeast, Northeast and North are below the Brazilian average. The latter region, with the worst results, does not even reach $70 \%$ of the services available in the states with the best service availability for equal need.

Although the results have shown some negative correlation between the deficit of health services and the respective GDPs per capita, this association was quite weak. The present study suggests that the disparities result from several other factors, which are not within the scope of this paper.

These discrepancies contrast with the Brazilian Constitutional principle of universal provision of health services. If, on the one hand, these results show discrepancies between intentions and reality, on the other hand, they indicate the direction compensatory policies should take. In this regard, the assessment of relative service deficits may serve to guide government action. This is especially important for the Brazilian health sector, where the government is responsible for meeting the demand for health services and solving any inequalities that arise, as established by the Brazilian laws.

Submitted in July 2003. Revised in March 2004. 
Relative deficit of health services in Brazilian states and regions

\section{References}

Ali, A. I. \& Seiford, L. M. 1990. "Translation Invariance in Data Envelopment analysis". Operations Research Letters, 9, 403405.

Banker, R. D., Charnes, A. \& Cooper, W. W. 1984. "Some Models for Estimating Technical and Scale Inefficiencies in Data Envelopment Analysis". Management Science, 13(9), 1078-1092.

Barros, E. B., Piola, S. F. \& Vianna, S. M. 1996. Política de Saúde no Brasil: Diagnóstico e Perspectivas. IPEA, Texto para Discussão 401. Brasília - DF.

Brasil. 1999. Constituição da República Federativa do Brasil (1988). Edição Atualizada. Brasília - DF.

Charnes, A., Cooper, W. W., Golany, B. Seiford, L. \& Stutz J. 1985. "Foundations of Data Envelopment Analysis for ParetoKoopmans Efficient Empirical Production Functions". Journal of Econometrics, 30, 91-107.

Charnes, A., Cooper, W. W. \& Rhodes, E. 1987. "Measuring the Efficiency of Decision Making Units". European Journal of Operational Research, 2, 429-444.

Charnes, A., Cooper, W. W. \& Rhodes, E. 1981. "Evaluating Program and Managerial Efficiency: an Application of Data Envelopment Analysis to Program Follow Through". Management Science, 27(6).

Dubeux, C. H. S. 2000. Parâmetros para a Qualidade dos Serviços de Saúde: o Caso do Pólo Médico do Grande Recife. Engenharia de Produção - CGT / UFPE, Dissertação de Mestrado. Recife PE.

Efron, B. 1979. "Bootstrap Methods: Another Look at the Jackknife". Ann. Statistics, 7, 1-26. 
Farrell, M. J. 1957. "The Measurement of Productive Efficiency. Journal of The Statistical Society", 120(3), 253-281.

Freitas, M. A. L. 2002. Viabilidade Econômica e Eficiência do Sistema de Saúde: o Caso do Pólo Médico da Cidade de Recife. PIMES / UFPE, Dissertação de Mestrado. Recife - PE.

Gasparini, C. E. \& Ramos, F. S. 2003. "Efetividade e Eficiência no Ensino Médio Brasileiro". Economia Aplicada, 7(2), p. 389-411. Grosskopf, S. 1996. "Statistical Inference and Non-parametric Efficiency: a Selective Survey". Journal of Productivity Analysis, 7, 161-176.

IBGE - Instituto Brasileiro de Geografia e Estatística. Censo Demográfico 2000: banco de dados. Disponível em <http://www. ibge.gov.br> Acesso em: 13 maio de 2002.

Kubrusly, L. S. 2002. Modelos Estatísticos. In: Kupfer, D. \& Hasenclever, L. Economia Industrial: Fundamentos Teóricos e Práticas no Brasil. Rio de Janeiro, Editora Campus.

Mariano, J. L. \& Sampaio, Y. 2002. "A Eficiência Técnica dos Colonos na Agricultura Irrigada no Vale do São Francisco". Economia Aplicada, 6(2), 265-285.

Marinho. 2001. A Avaliação da Eficiência Técnica nos Serviços de Saúde dos Municípios do Estado do Rio de Janeiro. IPEA, Texto para Discussão 842. Rio de Janeiro - RJ.

Marinho, A. \& Façanha, L. O. 2002. "Hospitais Universitários: Indicadores de Utilização e Análise de Eficiência". Economia Aplicada, 6(3), 607-638.

Marinho, A. \& Façanha, L. O. 2000. "Hospitais Universitários: Avaliação Comparativa de Eficiência Técnica". Economia Aplicada, 4(2), 315-349.

Marinho, A, Moreno, A. B. \& Cavalini, L. T. 2001. Avaliação 
Relative deficit of health services in Brazilian states and regions

Descritiva da Rede Hospitalar do Sistema Único de Saúde (SUS). IPEA, Texto para Discussão 848. Rio de Janeiro - RJ.

Marinho, A., Resende, M. \& Façanha, L. O. 1997. "Brazilian Federal Universities: Relative Efficiency Evaluation and Data Envelopment Analysis". Revista Brasileira de Economia, 51(4), 489-508.

Medeiros, M. 1999. Princípios de Justiça na Alocação de Recursos em Saúde. IPEA, Texto para Discussão 687. Rio de Janeiro RJ.

Medici, A. C. 1997. Perfil da Saúde no Brasil. IPEA, Texto para Discussão 472. Brasília - DF.

Ministério da Saúde. DATASUS: banco de dados. Disponível em $<$ http://www.datasus.gov.br $>$. Acesso em: abril e maio de 2002.

Pastor, J. 1996. "Translation Invariance in Data Envelopment Analysis: a Generalization". Annals of Operations Research, 66, 93-102.

Puig-Junoy, J. 1999. Radial Measures of Public Services Deficit for Regional Allocation of Public Funds. Department of Economics and Business, Health and Economics Research Centre (CRES), Universitat Pompeu Fabra. Mimeo. 1999.

Ramos F. S. \& Sampaio de Souza, M. C. 1999. Criação de Municípios e a Necessidade de Mensuração da Performance dos Gestores Públicos Municipais: O Caso do Nordeste. In Lima, J. P. R. (Org.). Economia e Região, Nordeste e Economia Regional: Ensaios. Recife, PE: Editora Universitária, 69-81.

Sampaio de Souza, M. C. \& Ramos, F. S. 1999. "Eficiência Técnica e Retornos de Escala na Produço de Serviços Públicos Municipais: o Caso do Nordeste e do Sudeste Brasileiro". Revista Brasileira de Economia, 53(4), 433-461. 
Seiford, L. M. \& Thrall, R. M. 1990. "Recent Developments in DEA: The Mathematical Programming Approach to Frontier Analysis". Journal of Econometrics, 46, 7-38.

Souza, G. S. 2001. "Statistical Properties of Data Envelopment Analysis Estimators of Production Functions". The Brazilian Review of Econometrics, 21(2), 291-322.

Souza, J. 1988. Análise em Componentes Principais e suas Aplicações. Brasília, Thesaurus. 
Relative deficit of health services in Brazilian states and regions

APPENDIX A - Indicators of the Availability of Public Health Services

CODE AVAILABILITY VARIABLES

Health professionals per number of inhabitants

K1 Doctors per 1,000 inhabitants

K2 Dentists per 1,000 inhabitants

K3 Nurses per 1,000 inhabitants

K4 Nutritionists per 1.000 inhabitants

K5 Nursing technicians per 1,000 inhabitants

Number of hospital beds per number of inhabitants

K6 $\quad$ Public hospital beds per 1,000 inhabitants

K7 $\quad$ ICU beds per 10,000 inhabitants

K8 Surgical beds per 10,000 inhabitants

K9 Obstetric beds per 10,000 inhabitants

K10 Clinic beds per 10,000 inhabitants

K11 Beds for prophylactic care per 10,000 inhabitants

K12 Psychiatric beds per 10,000 inhabitants

K13 Pediatric beds per 10,000 inhabitants 
Carlos Eduardo Gasparini and Francisco S. Ramos

APPENDIX B -

Indicators of the Demand for Public Health Services

CODE DEMAND VARIABLES

Morbidity and risk factors per number of inhabitants

N1 Confirmed cases of measles per 1,000,000 inhabitants

N2 Con firmed cases of diphtheria per 1,000,000 inhabitants

N3 Confirmed cases of whooping cough per 1,000,000 inhabitants

N4 Con firmed cases of neonatal tetanus per 1,000,000 inhabitants

N5 Con firmed cases of tetanus per 1,000,000 inhabitants

N6 Confirmed cases of yellow fever per 1,000,00 inhabitants

N7 Con firmed cases of rabies per 1,000,000 inhabitants

N8 Confirmed cases of hepatitis $B$ per 1,000,000 inhabitants

N9 Confirmed cases of cholera per 1,000,000 inhabitants

N10 Confirmed cases of dengue hemorrhagic fever per 1,000,000 inhabitants

N11 Con firmed cases of congenital syphilis per 1,000,000 inhabitants

N12 New cases of AIDS per 1,000,000 inhabitants

N13 New cases of tuberculosis per 1,000,000 inhabitants

N14 New cases of dengue per 1,000,000 inhabitants

N15 New cases of Hansen's disease per 1,000,000 inhabitants

N16 Cases of work-related diseases per 1,000,000 inhabitants

$N 17$ Cases of typical work-related accidents per 1,000,000 inhabitants

N18 Cases of road traffic accidents in the course of work per 1,000,000 inhabitants

N19 Cases of Hansen's disease per 1,000,000 inhabitants 
Relative deficit of health services in Brazilian states and regions

APPENDIX B - continued

Indicators of the Demand for Public Health Services

\section{CODE} DEMAND VARIABLES

Mortality per number of inhabitants

N20 Early neonatal mortality rate

N21 Late neonatal mortality rate

N22 Postnatal mortality rate

N23 Deaths from diarrheal diseases per 1,000,000 inhabitants

N24 Deaths from respiratory infection per 1,000,000 inhabitants

N25 Cases of circulatory diseases per 1,000,000 inhabitants

N26 Cases of malignant neoplasms per 1,000,000 inhabitants

N27 Number of work-related accidents per 1,000,000 inhabitants

N28 Cases of diabetes mellitus per 1,000,000 inhabitants

N29 Cases of cirrhosis per 1,000,000 inhabitants

N30 Cases of AIDS per 1,000,000 inhabitants

Socioeconomic and demographic variables

N31 Unemployment rate

N32 Fraction of the population living in poverty

N33 Income level

N34 Child labor rate

N35 Illiteracy rate

N36 Life expectancy at birth - male (inverse)

N37 Life expectancy at birth - female (inverse)

N38 Life expectancy at birth - general (inverse)

N39 Fraction of the population under 5 years of age

N40 Fraction of elderly people

$N_{41}$ Number of low birthweights per 1,000,000 inhabitants

N42 Percentage of households with piped water supply

N43 Percentage of households with sewage disposal

N44 Percentage of households with garbage collection 
Carlos Eduardo Gasparini and Francisco S. Ramos

\section{APPENDIX C -}

Results of the Principal Component Analysis

Regarding Availability Indicators

\begin{tabular}{|c|c|c|c|c|}
\hline \multirow[t]{2}{*}{ DESCRIPTION } & \multicolumn{4}{|c|}{ AVAILABILITY VARIABLES (1) } \\
\hline & $C_{1}$ & $C_{2}$ & $C_{3}$ & $C_{4}$ \\
\hline Eigenvalue & 12,450 & 6,205 & 2,482 & 1,600 \\
\hline Proportion & 0.512 & 0.255 & 0.102 & 0.066 \\
\hline Accumulated & 0.512 & 0.767 & 0.869 & 0.934 \\
\hline \multicolumn{5}{|l|}{ Eigenvector $\left(a_{j} i\right)$} \\
\hline$K 1$ & -0.009 & 0.192 & -0.064 & 0.271 \\
\hline$K 2$ & -0.010 & 0.086 & -0.069 & 0.112 \\
\hline K3 & 0.006 & 0.036 & -0.007 & 0.094 \\
\hline$K 4$ & -0.001 & 0.024 & -0.015 & 0.059 \\
\hline$K 5$ & -0.024 & 0.259 & -0.153 & 0.641 \\
\hline$K 6$ & -0.214 & 0.031 & 0.062 & 0.030 \\
\hline$K \gamma$ & -0.050 & 0.047 & -0.044 & 0.038 \\
\hline$K 8$ & -0.298 & 0.041 & 0.185 & 0.559 \\
\hline$K 9$ & -0.318 & -0.275 & 0.127 & -0.084 \\
\hline$K 10$ & -0.715 & -0.181 & -0.595 & $-0.11 \gamma$ \\
\hline$K 11$ & -0.108 & 0.286 & -0.099 & 0.065 \\
\hline$K 12$ & -0.358 & 0.756 & 0.316 & -0.367 \\
\hline$K 13$ & -0.331 & -0.348 & 0.669 & 0.126 \\
\hline
\end{tabular}

(1) Values were rounded up to three digits after the decimal point 
Relative deficit of health services in Brazilian states and regions

APPENDIX D -

Results of the Principal Component Analysis

Regarding Demand Indicators

\section{DESCRI}

Proportion

DEMAND VARIABLES

$(1)$

$C_{1} \quad C_{2}$

Accumulated

$7,572,641,000$

$1,647,805,000$

0.773

0.168

0.773

0.941

Eigenvector $\left(a_{j} i\right)$

\begin{tabular}{lrr}
\hline$N 1$ & -0.004 & -0.034 \\
$N 2$ & -0.000 & -0.000 \\
$N 3$ & -0.000 & 0.004 \\
$N 4$ & -0.000 & 0.000 \\
$N 5$ & 0.000 & 0.001 \\
$N 6$ & -0.000 & 0.000 \\
$N 7$ & -0.000 & 0.000 \\
$N 8$ & -0.005 & -0.012 \\
$N 9$ & 0.009 & 0.001 \\
$N 10$ & 0.000 & -0.000 \\
$N 11$ & 0.001 & -0.002 \\
$N 12$ & -0.008 & -0.045 \\
$N 13$ & -0.000 & 0.004 \\
$N 14$ & 0.987 & -0.137 \\
$N 15$ & -0.019 & 0.178 \\
$N 16$ & -0.009 & -0.061 \\
$N 17$ & -0.147 & -0.836 \\
$N 18$ & -0.015 & -0.074 \\
$N 19$ & -0.027 & 0.283 \\
$N 20$ & 0.001 & 0.003 \\
\hline
\end{tabular}


Carlos Eduardo Gasparini and Francisco S. Ramos

\begin{tabular}{lcc}
\hline Eigenvector $\left(a_{j} i\right)$ & & \\
\hline$N 21$ & 0.000 & 0.001 \\
$N 22$ & 0.002 & 0.002 \\
$N 23$ & 0.004 & 0.007 \\
$N 24$ & 0.000 & 0.001 \\
$N 25$ & -0.042 & -0.350 \\
$N 26$ & -0.030 & -0.179 \\
$N 27$ & -0.001 & -0.004 \\
$N 28$ & 0.001 & -0.032 \\
$N 29$ & -0.001 & -0.018 \\
$N 30$ & -0.004 & -0.022 \\
$N 31$ & 0.000 & -0.000 \\
$N 32$ & 0.002 & 0.007 \\
$N 33$ & 0.001 & 0.001 \\
$N 34$ & 0.000 & 0.002 \\
$N 35$ & 0.002 & 0.003 \\
$N 36$ & 0.000 & 0.000 \\
$N 37$ & 0.000 & 0.000 \\
$N 38$ & 0.000 & 0.000 \\
$N 39$ & 0.000 & 0.001 \\
$N 40$ & 0.000 & -0.001 \\
$N 41$ & -0.022 & -0.027 \\
$N 42$ & 0.000 & -0.006 \\
$N 43$ & -0.002 & -0.010 \\
$N 44$ & -0.001 & -0.007 \\
\hline
\end{tabular}

(1) Values were rounded up to three digits after the decimal point. 
